\title{
Leiomyosarcoma of the vulva: a case report
}

\author{
Angel Yordanov ${ }^{1}$, Stanislav Slavchev², Stoyan Kostov², Strahil Strashilov ${ }^{3}$, Ivan Ivanov ${ }^{4}$, \\ Margarita Nikolova ${ }^{5}$
}

${ }^{1}$ Department of Gynaecological Oncology, Medical University of Pleven, Bulgaria

${ }^{2}$ Department of Gynecology, Medical University of Varna, Bulgaria

${ }^{3}$ Department of Plastic Restorative, Reconstructive, and Aesthetic Surgery, Medical University of Pleven, Pleven, Bulgaria

${ }^{4}$ Department of General and Clinical Pathology, Medical University of Pleven, Bulgaria

${ }^{5}$ Saint Marina University Hospital, Medical University Pleven, Pleven, Bulgaria

\section{Abstract}

Introduction: Leiomyosarcoma of the vulva is a rare disease accounting for about $1 \%$ of all primary vulvar neoplasia but it is the most common type of vulvar sarcomas. Usually it arises from the smooth muscles, blood vessels, rough ligaments, and erector-pili muscles. No treatment algorithms have been established yet. Tumour excision with clean resection lines is considered sufficient, with radiation therapy applied in certain cases.

Case report: We report a case of a 73-year old patient in whom the disease was manifested by pain syndrome and rapidly growing mass with irregular margins in the symphysis area and satellite nodules. She underwent extensive local excision followed by radiation therapy.

Discussion: Isolated cases and limited series of LMS cases have been described in literature. Leiomyosarcoma is most commonly localized to the labia majora, the Bartholin gland area, clitoris and labia minora. It most often affected perimenopausal women but in younger and pregnant patients was described. The diagnosis is not always easy and different histological markers has to be used. There are no definitive therapeutic algorithms due to the rarity of the disease. The management is surgical treatment and the entire tumour must be removed with histologically verified clean resection margins, followed by radiation therapy in some cases.

Conclusions: Vulvar tumours are difficult to distinguish macroscopically. Accurate histological diagnosis allows adequate treatment.

Key words: vulvar leiomyosarcoma, diagnosis, treatment.

\section{Introduction}

Leiomyosarcoma (LMS) of the vulva is a rare disease representing $1 \%$ of all primary vulvar neoplasms. Still, it is the most common type of vulvar sarcomas [1-3]. It occurs usually in the Bartholin's gland area, and its clinical picture is similar to that of bartholinitis which can be diagnostically challenging [4]. It is more common in middle-aged or older women [5]. Most of the described cases had been reported in Western countries, pointing to the conclusion of a possible etiopathogenetic link to lifestyle or genetic predisposition [5]. Leiomyosarcoma can arise from the smooth muscles, the walls of blood vessels, rough ligaments, and erector-pili muscles [6-8].

Isolated cases and limited series have been described in research literature [7, 9-12], leading to a lack of consensus on both surgical treatment and adjuvant radiotherapy and/or chemotherapy.
We present a case of a 73-year old patient hospitalised for surgical treatment due to a painful fast-growing formation in the symphysis area.

\section{Case report}

A 73-year old patient was admitted to the clinic with a formation with irregular margins in the symphysis area, with dimensions of $7 / 5 \mathrm{~cm}$ and satellite nodules $20 \mathrm{~mm}$ in diameter on average (Fig. 1).

Arterial hypertension and previous cholecystectomy were reported in anamnesis. The formation has been present for several years but in the last 3 months it has started to grow rapidly (it has doubled in size), accompanied by pain. Radiography of the lungs, abdominal ultrasound, and CT of the small pelvis did not show any abnormalities. After standard preoperative preparation, 


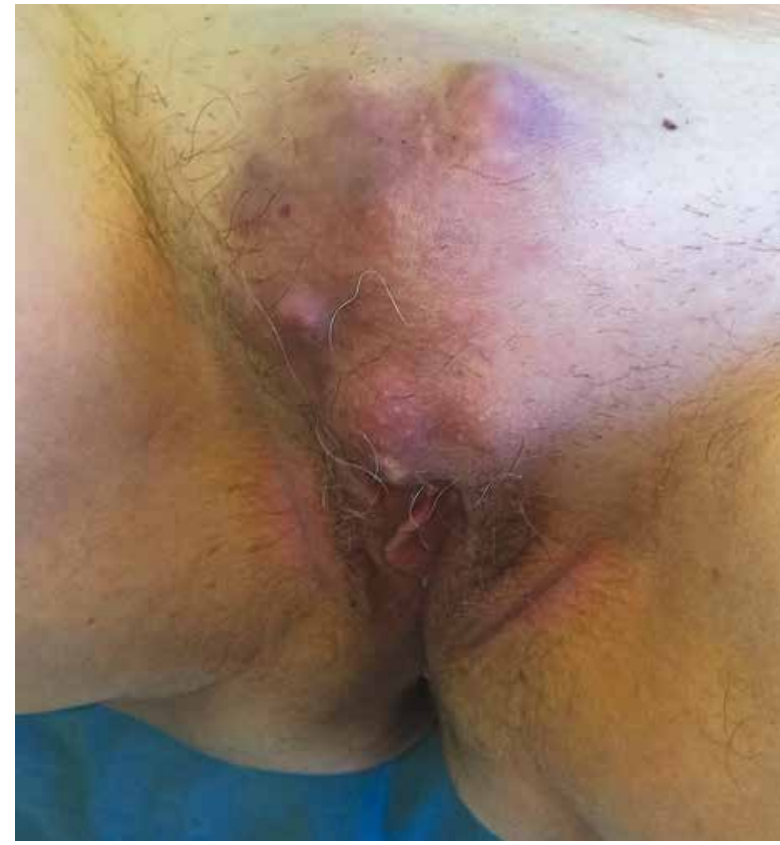

Fig. 1. Macroscopic view of the tumour

a wide local excision of the described formation was performed (Figs. 2 and 3).

Microscopic examination showed subcutaneous infiltration of an overtly malignant mesenchymal tumour. Part of the parenchyma was represented by elongated cells with pronounced cellular and nuclear atypia, forming chaotically intertwined bundles, areas of tumour necrosis and single mitotic figures. In many fields, the cells were markedly rhabdoid in appearance, large with abundant eosinophilic cytoplasm, and excentric polymorphic nuclei, which aroused suspicion of rhabdomyosarcoma. We diagnosed leiomyosarcoma, based on the morphological and IHC testing: SMA /+/, S100 /-/ and MyoD1 /-/ (Figs. 4 and 5).

The patient was discharged on day 2 postoperatively and referred for radiotherapy.

\section{Discussion}

The incidence of vulvar sarcomas varies between $1.5 \%$ and $5 \%$ of all vulvar neoplasms, with LMS being the most frequent histological type $[1,13]$. Other vulvar sarcomas include embryonal and alveolar rhabdomyosarcoma, epithelioid sarcoma, alveolar soft part sarcoma, and other rare sarcomas [4, 14].

Isolated cases and limited series of LMS cases have been described in literature and the largest series (25 cases) was reported by Aartsen and AlbusLutter [10].

LMS is most commonly localized to the labia majora, the Bartholin gland area, clitoris and labia minora [15]. LMS can affect all age groups and most often involves perimenopausal women [10]. The youngest

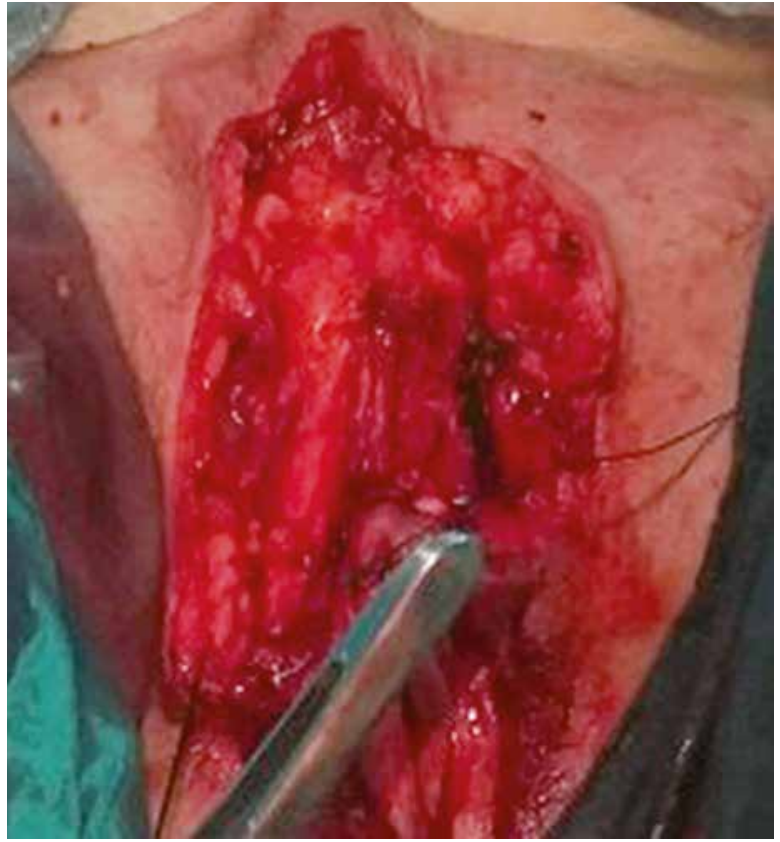

Fig. 2. Operative wound

patient reported with the disease is a 14-year old [11]; some cases of leiomyosarcoma during pregnancy have been described as well [12]. Most of the reported cases had been identified in Western countries, indicating a potential association to lifestyle or genetic predisposition [5]. A possible involvement of chronic inflammation to LMS has been discussed [16]. LMS cases associated to lichen sclerosus have been reported [17].

Clinically, this tumour usually presents itself as an asymptomatic solid formation 1.5 to $16 \mathrm{~cm}$ in size, and may rarely be accompanied by bleeding or urinary problems [4, 7]. Bartholin cyst, infectious granuloma, fibroma, lipoma, or myomas should be considered in the differential diagnosis [18]. Improper diagnosis leads to inadequate treatment. Accurate diagnosis is made histologically. Unfortunately, there is no single

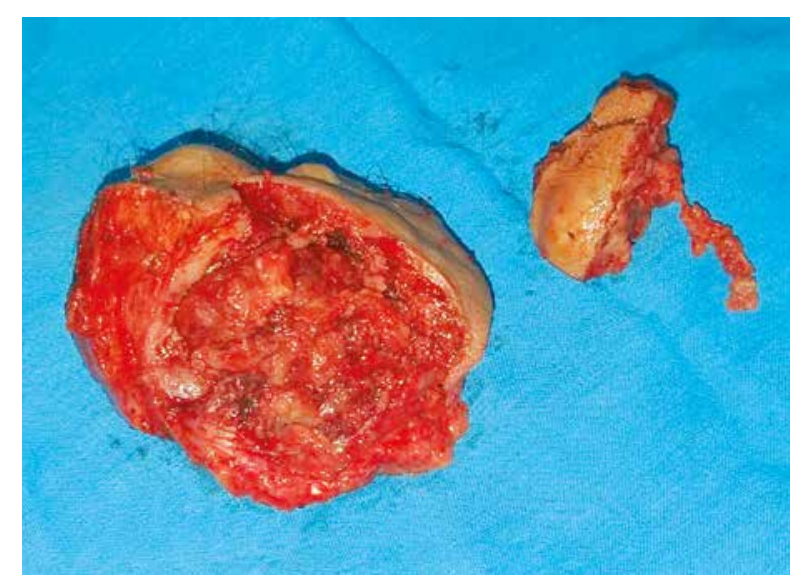

Fig. 3. The specimen (main tumour and satellite nodule) 


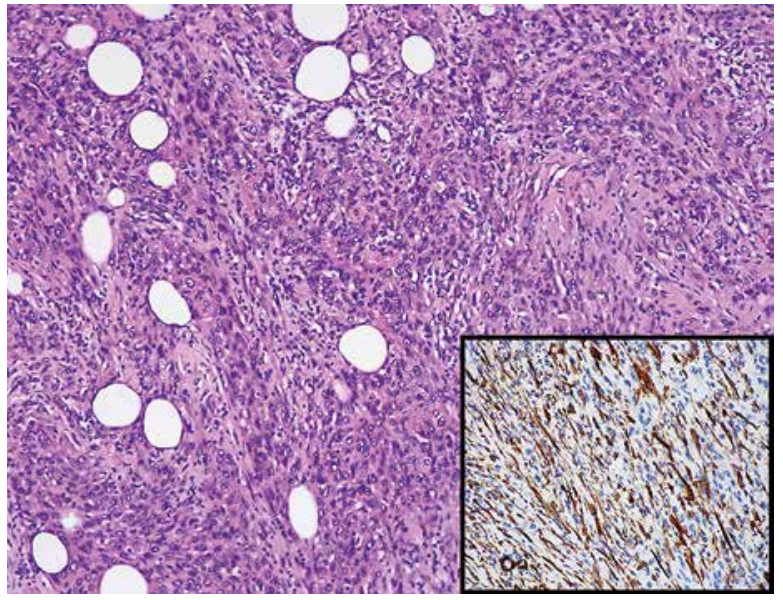

Fig. 4. Classical picture of leiomyosarcoma manifested by elongated cells with moderate nuclear polymorphism and abundant eosinophilic cytoplasm. XE $\times 0.25$; cytoplasmic expression for SMA (insertion $\times 0.40$ )

morphological feature that clearly separates benign from malignant genital smooth muscle tumours. The most commonly used modified scheme for histological diagnosistoday is that of the Stanford researchers [19]. They introduced tumour cell necrosis coagulation as an additional feature to hitherto used mitotic index [20], and cellular atypism [21]. The latest 2014 WHO classification of tumours of the female reproductive organs also indicates size over $5 \mathrm{~cm}$ and invasive growth [14, 22, 23]. Immunohistochemical (IHC) testing is important in diagnosis as the smooth muscle nature of the tumour is not always obvious, as it was in our case. Desmin, smooth muscle actin and k-caldesmon [14] are most often positive.

There are no definitive therapeutic algorithms due to the rarity of the disease. The management is surgical treatment and the entire tumour must be removed with histologically verified clean resection margins, followed by radiation therapy which is not necessary in low-grade LMS [24, 25]. The administration of chemotherapy is not quite clear yet; it is considered that it may reduce the risk of recurrence or metastasis [26]. Radical tumour removal and the absence of metastases provide good prognosis $[24,26]$. Some authors believe that lymphatic dissection should be performed [1, 6]. LMS has the ability to metastasize hematogenously and to recur [8].

In our case, the patient was significantly older than the average age reported for the disease and had a pronounced pain symptom, which we attribute to the necrotic changes caused by the rapid tumour growth. We performed extensive local excision followed by radiation therapy. Three months later, the patient is well with no evidence of recurrence.

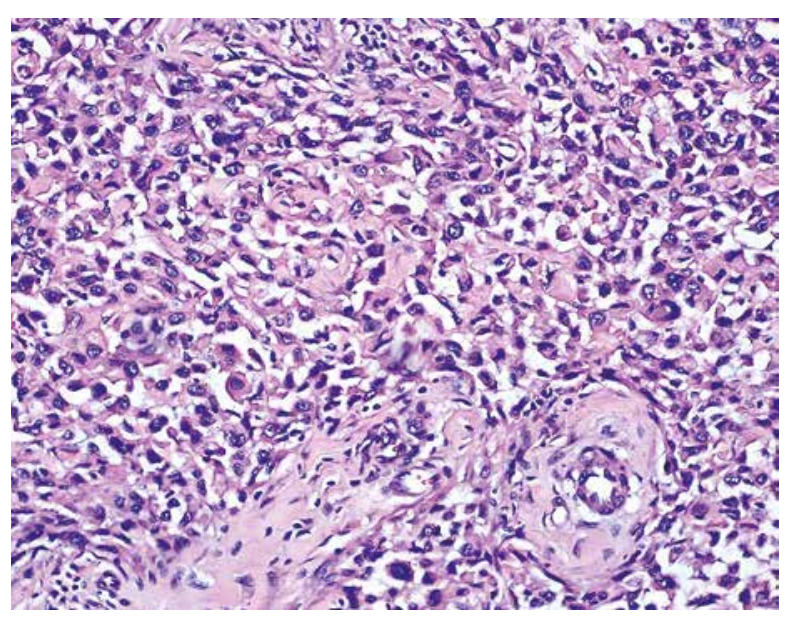

Fig. 5. Population of rhabdoid elements in the tumour parenchyma Xe $\times 0.40$

\section{Conclusions}

Vulvar tumours cannot always be macroscopically diagnosed as malignant or benign. In many cases, differentiation is difficult even in histological examination, which is the main diagnostic method. Malignancy and histogenesis of these tumours are not always obvious. This makes them unsuitable for express histological testing (freeze-drying of tissue) during surgical treatment. Accurate diagnosis allows adequate disease management and treatment.

\section{Disclosure}

The authors report no conflict of interest.

\section{References}

1. Curtin JP, Saigo P, Slucher B, et al. Soft-tissue sarcoma of the vagina and vulva: a clinicopathologic study. Obstet Gynecol 1995; 86: 269-272.

2. DiSaia PJ, Pecorelli S. Gynecological sarcomas. Semin Surg Oncol. 1994;10(5): 369-373. doi:10.1002/ssu.2980100510

3. Tavassoli FA, Norris HJ. Smooth muscle tumors of the vulva. Obstet Gynecol 1979; 53: 213-217.

4. González-Bugatto F, Añón-Requena MJ, López-Guerrero MA, et al. Vulvar leiomyosarcoma in Bartholin's gland area: A case report and literature review. Arch Gynecol Obstet 2009; 279: 171-174.

5. Mensch LS, Trask CE, Eltabbakh GH. Leiomyosarcoma of the vulva: A brief communication. Eur J Gynaecol Oncol 2000; 21: 61.

6. Salehin D, Haugk C, William M, et al. Leiomyosarcoma of the vulva. Eur J Gynaecol Oncol 2012; 33: 306-308.

7. Dewdney S, Kennedy CM, Galask RP. Leiomyosarcoma of the vulva: A case report. J Reprod Med 2005; 50: 630-632.

8. Shankar S, Todd PM, Rytina E, Crawford RA. Leiomyosarcoma of the vulva. J Eur Acad Dermatol Venereol 2006; 20: 116-117.

9. Davos I, Abell MR. Soft tissue sarcomas of vulva. Gynecol Oncol 1976; 4: 70-86

10. Aartsen EJ, Albus-Lutter CE. Vulvar sarcoma: clinical implications. Eur J Obstet Gynecol Reprod Biol 1994; 56: 181-189 
11. Torres Lobaton A, Cruz Ortiz H, Rojo Herrera G, Avila Medrano L. Sarcomas of the vulva. Report of 2 cases. Ginecol Obstet Mex 2000; 68: 429-434 (article in Spanish).

12. Di Gilio AR, Cormio G, Resta L, et al. Rapid growth of myxoid leiomyosarcoma of the vulva during pregnancy: a case report. Int J Gynecol Cancer 2004; 14: 172-175.

13. Newman PL, Fletcher CD. Smooth muscle tumours of the external genitalia: clinicopathological analysis of a series. Histopathology 1991; 18: 523-529.

14. Nucci MR, Ganesan R, McCluggage WG, et al. Soft tissue tumors of the vulva. In: Kurman RJ, Carcangiu ML, Herrington CS, Young RH (eds.), WHO Classification of Tumors of Female Reproductive Organs, $4^{\text {th }}$ ed IARC, Lyon, France 2014: 243-249.

15. Androutsopoulos G, Adonakis G, Ravazoula P, et al. Leiomyosarcoma of the vulva: a case report. Eur J Gynaecol Oncol 2005; 26: 577-578.

16. Chokoeva AA, Tchernev G, Cardoso JC, et al. Vulvar sarcomas: Short guideline for histopathological recognition and clinical management. Part 1. Int J Immunopathol Pharmacol 2015; 28: 168-177.

17. Rawal N, Saridogan E, Khan N, Weekes A. Leiomyosarcoma of the vulva in association with lichen sclerosus. J Obstet Gynaecol 2005; 25: 87-88.

18. Tjalma WA, Hauben El, Deprez SM, et al. Epithelioid sarcoma of the vulva. Gynecol Oncol 1999; 73: 160-164.

19. Bell SW, Kempson RL, Michael R. Problematic uterine smooth muscle neoplasms: a clinicopathologic study of 213 cases. Am J Surg Pathol 1994; 18: 535-558.

20. Taylor H, Norris H. Mesenchymal tumors of the uterus: IV. Diagnosis and prognosis of leiomyosarcomas. Arch Pathol 1966; 82: 40-44.

21. Kempson R, Barri W. Uterine sarcomas: classification, diagnosis and prognosis. Hum Payhol 1970; I: 331-349.

22. Kempson RL, Hendrickson MR. Smooth muscle, endometrial stromal, and mixed müllerian tumors of the uterus. Mod Pathol 2000; 13: 328342

23. Gincheva D, Nikolova M, Gorchev G, Tomov S. Uterine Smooth Muscle Tumors - Determination of Clinical Behavior and Classification Akush Ginekol (Sofiia) 2014; 53: 40-46.

24. Williams NP, Williams E, Fletcher H. Smooth muscle tumours of the vulva in Jamaica. West Indian Med J 2002; 51: 228-231.

25. Patnayak R, Manjulatha B, Srinivas S, et al. Leiomyosarcoma of the vulva. Indian J Pathol Microbiol 2008; 51: 448-449.

26. Otoide V, Okobia M, Aligbe J, Okonofua F. Vulvar leiomyosarcoma: a case report in a Nigerian woman. Surg Technol Int 2002; 10: 71-73. 